Article

\title{
Effect of Pulse Current-Assisted Rolling on the Interface Bonding Strength and Microstructure of $\mathrm{Cu}$ /Al Laminated Composite
}

\author{
Hao Song ${ }^{1,2}$, Weixin Hao ${ }^{3, *}$, Xiaowei Mu ${ }^{4}$, Tingzhuang Han ${ }^{1,2}$, Chaojie Che ${ }^{1,2}$ \\ and Guihong Geng ${ }^{5}$ \\ 1 The Coordinative Innovation Center of Taiyuan Heavy Machinery Equipment, Taiyuan University of Science \\ and Technology, Taiyuan 030024, China; B20170008@stu.tyust.edu.cn (H.S.); 2018013@tyust.edu.cn (T.H.); \\ 2019002@tyust.edu.cn (C.C.) \\ 2 Shanxi Provincial Key Laboratory of Metallurgical Equipment Design and Technology, Taiyuan University of \\ Science and Technology, Taiyuan 030024, China \\ 3 School of Materials Science and Engineering, Taiyuan University of Science and Technology, \\ Taiyuan 030024, China \\ 4 Zhejiang Highway Technicians College, Hangzhou 310023, China; muxiaowei2008@126.com \\ 5 School of Materials Science and Engineering, North Minzu University, Yinchuan 750000, China; \\ gengguihong@nmu.edu.cn \\ * Correspondence: 1989004@tyust.edu.cn
}

Received: 8 September 2020; Accepted: 14 November 2020; Published: 23 November 2020

\begin{abstract}
In this paper, $\mathrm{Cu} / \mathrm{Al}$ laminated composite was prepared by adopting the pulse current-assisted rolling method, and the microstructure and mechanical properties of the material were investigated. The results showed that the $\mathrm{Cu} / \mathrm{Al}$ laminated composite with pulsed current was significantly strengthened. The composite interface of $\mathrm{Cu} / \mathrm{Al}$ laminated composite with pulse current-assisted rolling was found without intermetallic phase, and its bonding mode was mainly mechanical combined. The number of reticulated ridges increased at the shear interface. The small cracks on the copper surface were firmly embedded in the aluminum metal. There were obvious folds on the copper surface without aluminum embedding. The structural change of the bonding interface increases the contact area between copper sheet and aluminum sheet, thereby enhancing the bonding strength of the $\mathrm{Cu} / \mathrm{Al}$ laminated composite.
\end{abstract}

Keywords: shear strength; pulse current; $\mathrm{Cu} / \mathrm{Al}$ laminated composite; combined interface

\section{Introduction}

$\mathrm{Cu} / \mathrm{Al}$ laminated composite is a conductive material with stable performance, high electrical conductivity, easy forming and processing, and stable output performance. It was widely used in petroleum, electronics, aerospace, new energy and other industrial fields due to its advantages of less impact on the environment and corrosion resistance [1-3]. At present, the methods of rolling $\mathrm{Cu} / \mathrm{Al}$ laminated composites include hot-rolled composite, cold-rolled composite, explosive composite and so on [4-6]. Wide processing range and high production efficiency are the advantages of cold rolling composite process [7-9].

In recent years, domestic and foreign researchers have also done a lot of research in order to improve the bonding strength of $\mathrm{Cu} / \mathrm{Al}$ laminated composites. Temperature [10], heat treatment [11] and vacuum rolling [12] have also achieved good results. Naseri et al. [13] studied the influence of thickness, number of brass layers, friction conditions and annealing after rolling on bond strength. Hongjun et al. [14] studied the effect of surface treatment before rolling on the rolling compound effect. 
The results show that the brushing treatment has the greatest influence on the composite effect, and the acid-base washing treatment has the least influence. Chih-Yuan et al. [15] studied the influence of the development of interface structure on the fracture mechanism and bonding strength of cold rolled $\mathrm{Cu} / \mathrm{Al}$ bimetallic plates. $\mathrm{Cu} / \mathrm{Al}$ bimetallic plates were made by cold roll welding and sintered under different conditions. As the sintering temperature and sintering time increase, the bonding strength of the $\mathrm{Cu} / \mathrm{Al}$ bimetallic plate generally increases to the maximum value first, and then decreases to a lower value. Tomokatsu Aizawa [16] introduced a new type of welding process for aluminum sheet and copper sheet. When the discharge current of the capacitor bank passes through the flat double-coiled coil, magnetic flux suddenly occurs around the coil. Eddy currents are generated between the overlapping aluminum and copper sheets on the coil. The electromagnetic force acts on the aluminum sheet, so that collision and welding occur between the aluminum sheet and the copper sheet. Morteza Sarvari et al. [17] took the collision surfaces and interfaces of MPW of pure aluminum and pure copper as research objects. The results revealed that the metallurgical bonding was obtained in the air gap of $0.7 \mathrm{~mm}$, whereas higher air gaps (1 to $4 \mathrm{~mm}$ ) result in debonding due to higher impact energy. As a brand-new physical processing method, pulse current processing technology has drawn a great deal of attention because of its environmental protection and process operability [18-20].

At present, there are few studies on electrical pulse-assisted rolling of $\mathrm{Cu} / \mathrm{Al}$ laminated composites. For this reason, the bonding strength of $\mathrm{Cu} / \mathrm{Al}$ laminated composites under different rolling processes has been studied in our lab. The advantages of this new process were determined by the use of electrical pulses to assist the rolling of $\mathrm{Cu} / \mathrm{Al}$ layered composites.

\section{Experimental Procedure}

The test materials were 1060 aluminum sheet with a thickness of $4 \mathrm{~mm}$ and T2 copper sheet with a thickness of $1.5 \mathrm{~mm}$. Their chemical compositions are shown in Tables 1 and 2 . Their mechanical properties are shown in Table 3 . The size of aluminum sheet was $160 \mathrm{~mm} \times 30 \mathrm{~mm} \times 4 \mathrm{~mm}$. The size of the copper sheet was $160 \mathrm{~mm} \times 30 \mathrm{~mm} \times 1.5 \mathrm{~mm}$. A 30-degree ramp was machined on the narrow side of the aluminum sheet before the combined slab. Before rolling, the raw materials were polished with scratch brushing and the surface was repeatedly washed with acetone and alcohol to remove the adhering pollution [21].

Table 1. Chemical composition of $\mathrm{T} 2$ copper (\%)

\begin{tabular}{cccccccc}
\hline & \multicolumn{7}{c}{ T2 wt. \% } \\
\hline Fe & AS & $\mathbf{S b}$ & $\mathbf{B i}$ & $\mathbf{P b}$ & $\mathbf{S}$ & $\mathbf{C u}$ & Impurity Content \\
\hline 0.0036 & 0.0013 & 0.0015 & 0.0008 & 0.0038 & 0.0044 & 99.91 & $<0.1$ \\
\hline
\end{tabular}

Table 2. Chemical composition of $\mathrm{Al}$ sheet (\%)

\begin{tabular}{ccccccccc}
\hline \multicolumn{8}{c}{ Al wt. \% } \\
\hline Fe & Zn & Si & Cu & Mg & Ti & Mn & V & Al \\
\hline 0.19 & 0.025 & 0.13 & 0.023 & 0.011 & 0.013 & 0.014 & 0.032 & 99.6 \\
\hline
\end{tabular}

Table 3. Mechanical properties of $\mathrm{Al}$ and $\mathrm{Cu}$ materials.

\begin{tabular}{cccccc}
\hline Material & Elastic Modulus E/GPa & Shear Modulus G (GP) & Poisson's Ratio $\mu \mathrm{m}$ & Yield Strength $\sigma_{\mathbf{s}} / \mathbf{M P a}$ Tensile Strength $\sigma_{\mathbf{b}} / \mathbf{M P a}$ \\
\hline $\mathrm{Cu}$ & 128 & 48 & 0.34 & 82 & 259 \\
\hline $\mathrm{Al}$ & 62 & 25 & 0.33 & 45 & 113 \\
\hline
\end{tabular}

The experiment was performed on a rolling mill with a roll diameter of $100 \mathrm{~mm}$. The motor rated power of the rolling mill was $3 \mathrm{~kW}$. A pulse current device was installed on the rolling mill used in the experiment. The pulse parameters were a pulse voltage of $380 \mathrm{~V}$, a pulse width of $40 \mu \mathrm{s}$, and a 
pulse frequency of $800 \mathrm{~Hz}$. A single pass and large deformation process was used in the experiment. The rolling speed was maintained at $0.2 \mathrm{~m} / \mathrm{s}$ and the deformation rate was $65 \%$. The rolling was performed at room temperature. The final height of $\mathrm{Cu} / \mathrm{Al}$ laminated composite was $1.925 \mathrm{~mm}$ after rolling in two processes. The shape of $\mathrm{Cu} / \mathrm{Al}$ Laminated composite after rolling was shown in Figure 1.

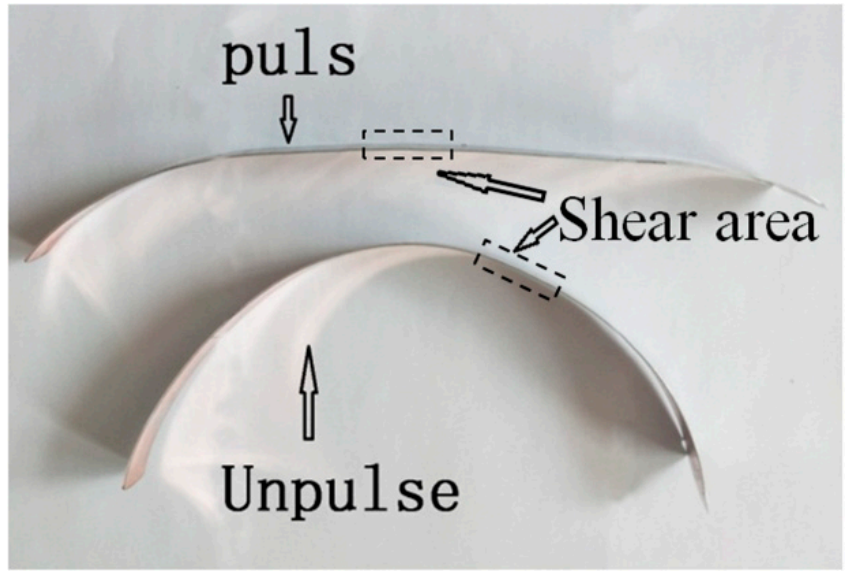

Figure 1. Shape of $\mathrm{Cu} / \mathrm{Al}$ laminated composite after rolling.

The shear strength of composite sheet was tested by electronic universal tensile testing machine (MTS, jinan, China). The tested specimen was single lap. The length of the single lap bonding surface was $20 \mathrm{~mm}$ and the width was $1.4 \mathrm{~mm}$. The shearing process uses constant velocity stress at a speed of $1 \mathrm{MPa} / \mathrm{s}$. To improve the accuracy of the experimental data, the shear experimental data is the average result of 5 measurements, and the quoted error is the standard deviation. The interface morphology of the shear interface was observed by VHX-2000 super depth of field 3D microscope system. The interface morphology and composition of the sheared interface of the laminated composite were detected by Scanning Electron Microscope (SEM, ZEISS, Jena, Germany). The Energy Dispersive Spectrometer (EDS) attached to the electron microscope was used to analyse the element distribution of the interface. Sanding and mechanical polishing of the longitudinal surface of the $\mathrm{Cu} / \mathrm{Al}$ laminated composite were performed in the rolling direction. The interface morphology and component scanning of laminated composite longitudinal surface were detected by Scanning Electron Microscope (SEM) and Electron Backscatter Diffraction (EBSD). The element distribution of the interface was analysed by Energy Dispersive Spectrometer (EDS, Oxford Instruments, Abingdon, UK).

\section{Results and Discussion}

The shear strength of the laminated composite is one of the criteria for evaluating the bonding strength. Therefore, the shear strength was used to reflect the bonding strength of the $\mathrm{Cu} / \mathrm{Al}$ laminated composite. The shear strength of $\mathrm{Cu} / \mathrm{Al}$ laminated composite under different rolling processes was tested. The schematic diagram of the shear sample is shown in Figure 2. The length and width of the shear specimen were $71.4 \mathrm{~mm}$ and $1.925 \mathrm{~mm}$, respectively. The length of the connecting area in the middle of the specimen was $1.4 \mathrm{~mm}$.

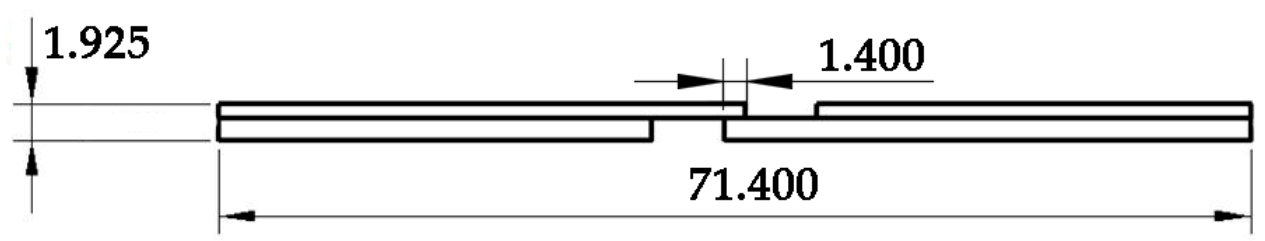

Figure 2. Schematic diagram of shearing sample (units: $\mathrm{mm}$ ). 


\subsection{The Combined Performance under Different Rolling Processes}

The comparison experiment of rolled $\mathrm{Cu} / \mathrm{Al}$ laminated composite was carried out by applying pulse current on the basis of traditional cold rolling process and traditional cold rolling process. The change in shear strength under different rolling processes is shown in Figure 3.

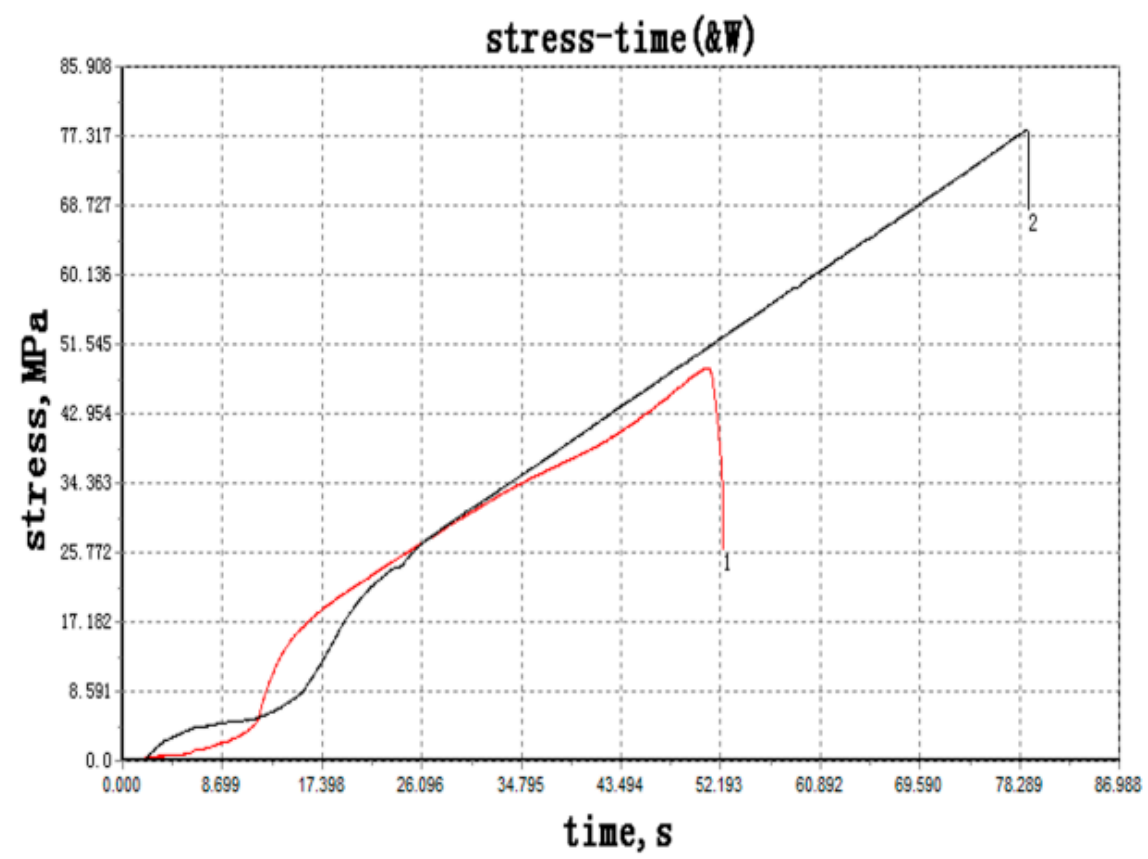

Figure 3. Shear curves of different rolling processes: (1) unpulsed; (2) pulse.

Figure 3 shows the change curve of the shear strength of $\mathrm{Cu} / \mathrm{Al}$ laminated composite. Curve 1 is the shear curve of $\mathrm{Cu} / \mathrm{Al}$ laminated composite without pulse current-assisted rolling. Curve 2 is the shear curve of $\mathrm{Cu} / \mathrm{Al}$ laminated composite rolled with pulse current-assisted rolling. It can be seen from Figure 3 and Table 4 that the shear strength of $\mathrm{Cu} / \mathrm{Al}$ laminated composite without pulse current-assisted rolling was relatively lower. The shear strength of the specimen was $48.57 \pm 1.41 \mathrm{MPa}$ and the shear force was $2.392 \pm 0.053 \mathrm{kN}$. The $\mathrm{Cu} / \mathrm{Al}$ laminated composite has high shear strength when applied in pulse current-assisted rolling. The shear strength of the specimen was $78.10 \pm 1.87 \mathrm{MPa}$ and the shear force was $3.53 \pm 0.085 \mathrm{kN}$. It indicates that pulse assisted rolling enhances the bonding performance of laminated composite.

Table 4. Shearing strength in bonding zone of $\mathrm{Cu} / \mathrm{Al}$ laminated composite.

\begin{tabular}{ccc}
\hline Rolling Process & Shear Resistance (kN) & Shear Strength (MPa) \\
\hline Unpulsed & $2.392 \pm 0.069$ & $48.57 \pm 1.41$ \\
pulse & $3.53 \pm 0.085$ & $78.10 \pm 1.87$ \\
\hline
\end{tabular}

Figure 4 shows the phase diagram of the bonding interface of $\mathrm{Cu} / \mathrm{Al}$ laminated composite. It can be seen from the figure that only copper phase and aluminum phase can be seen in the interface of $\mathrm{Cu} / \mathrm{Al}$ laminated composite, and it was difficult to found other phases. It shows that the interface bonding of $\mathrm{Cu} / \mathrm{Al}$ laminated composite was dominated by mechanical bonding under these two processes. The obvious increase in shear strength was mainly caused by the improvement of the mechanical bonding morphology. 

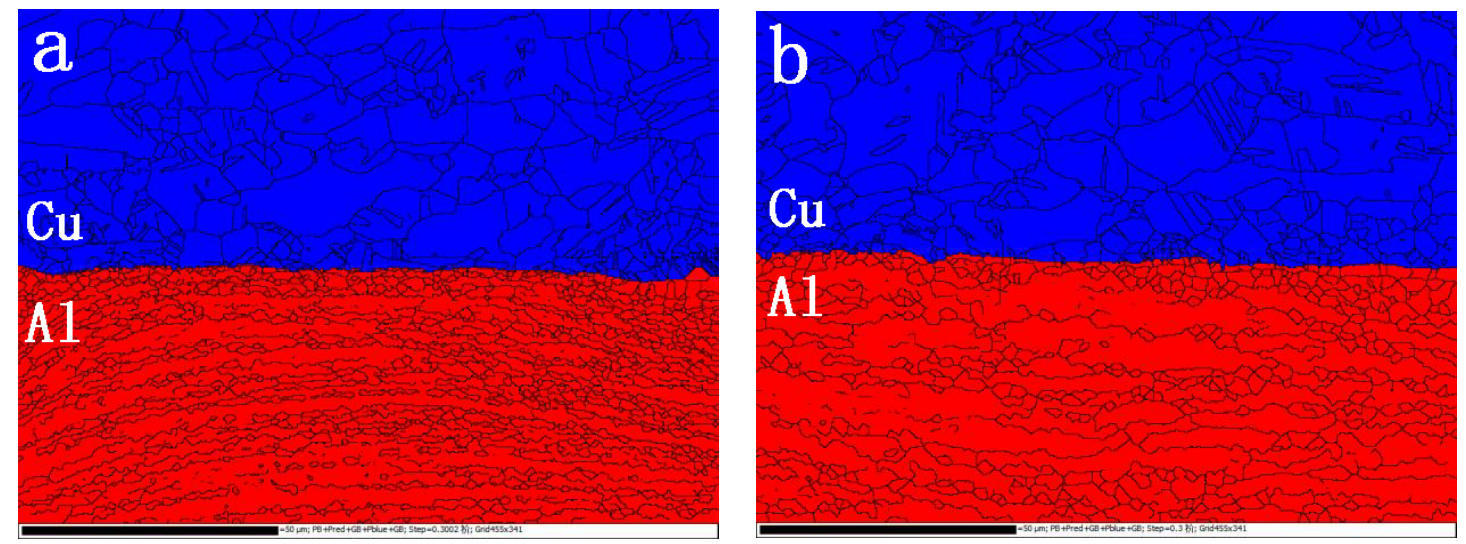

Figure 4. Electron Backscatter Diffraction (EBSD) grain boundary maps of the interface of the $\mathrm{Cu} / \mathrm{Al}$ laminated composite: (a) unpulsed; (b) pulse.

\subsection{The Effect of Different Rolling Processes on the Shear Interface}

Figure $5 \mathrm{a}, \mathrm{c}$ shows the morphology of the copper-side interface and the aluminum-side interface after shear test of the $\mathrm{Cu} / \mathrm{Al}$ laminated composite without pulse assisted rolling. It can be seen from Figure $5 \mathrm{a}$ that there were reticulated ridges on the shear surface of the copper side. After EDS testing, the ridge was found to be pure aluminum. For $\mathrm{Cu} / \mathrm{Al}$ rolled composites, copper sheets have relatively high hardness and relatively poor resistance to plastic deformation. The surface oxide layer was removed on the contact surface of aluminum and copper by surface cleaning treatment before rolling. At the same time, a thin hardened layer was presented on the contact surface. The relationship between the hardened layer of copper and the copper matrix under the hardened layer was destroyed during the rolling process. The plasticity of the hardened layer of copper was relatively poor. It cannot deform synchronously with the copper matrix. The interface between the copper sheet and the aluminum sheet was affected by the rolling force and friction during the rolling process. The hardened layer on the copper surface was cracked under the combined action of these forces, and cracks of various sizes were formed. The deformation resistance of the aluminum sheet was relatively low. The aluminum sheet first produced plastic deformation under the action of radial rolling force. The aluminum was squeezed into the copper crack to fill the gap. The aluminum extended and adhered to the copper, and a metal bonding area with a large bonding force was formed in the crack. Figure 5 a the reticulated ridge was formed due to the retention of aluminum in the crack after tearing. There were elongated cracks in the area A (Figure 5a), indicating that these small cracks were not firmly embedded in the aluminum metal during the rolling process. Figure $5 b$,d show the morphology of the copper-side interface and the aluminum-side interface after shear test of the $\mathrm{Cu} / \mathrm{Al}$ laminated composite with pulse assisted rolling. It can be seen from Figure $5 \mathrm{~b}$ that the density of the reticulated ridges on the bonding surface of the $\mathrm{Cu} / \mathrm{Al}$ laminated composite was significantly increased by applying pulse current-assisted rolling. The pulse current was inputted to assist the rolling of the $\mathrm{Cu} / \mathrm{Al}$ laminated composite in an instant and high-energy manner. The ability of atoms to vibrate was enhanced by gained energy inside the copper metal. The movement speed of the dislocation was accelerated, and the tangle between the dislocations was opened. In this way, the internal friction force during metal deformation can be greatly reduced, thereby improving the plastic deformation ability of copper. The copper sheet had greater elongation at the same deformation rate. The difference in deformation was further increased between the hardened layer on the copper surface and the copper matrix. The number of cracks on the copper surface where the copper sheet and the aluminum sheet contact each other increased under the combined action of rolling force and friction force. More aluminum was squeezed into the copper cracks under the influence of radial rolling pressure. Aluminum was stretched and adhered to the copper in the crack, thereby forming more metal bonding areas. The proportion of direct contact area increased between copper and aluminum. In the shear experiment, $\mathrm{Cu} / \mathrm{Al}$ laminated composite produces plastic strain 
and displacement under the action of shear force. Relative slippage occurs between the aluminum metal that penetrates into the copper crack and the copper sheet. The pulling force of aluminum embedded in copper was mobilized. The tensile force is transmitted to the copper sheet through the friction between the aluminum embedded in the copper and the copper sheet, so that the copper on both sides of the crack remains stable under the connection of aluminum to achieve the purpose of enhancing the shear strength. The deep sliding of the copper sheet was effectively prevented under the anchoring effect. The density of the reticulated ridges on the copper side was obviously increased, indicating that the number of cracks on the copper sheet increased by pulse current-assisted rolling. The shear strength of $\mathrm{Cu} / \mathrm{Al}$ laminated composite was greatly improved.
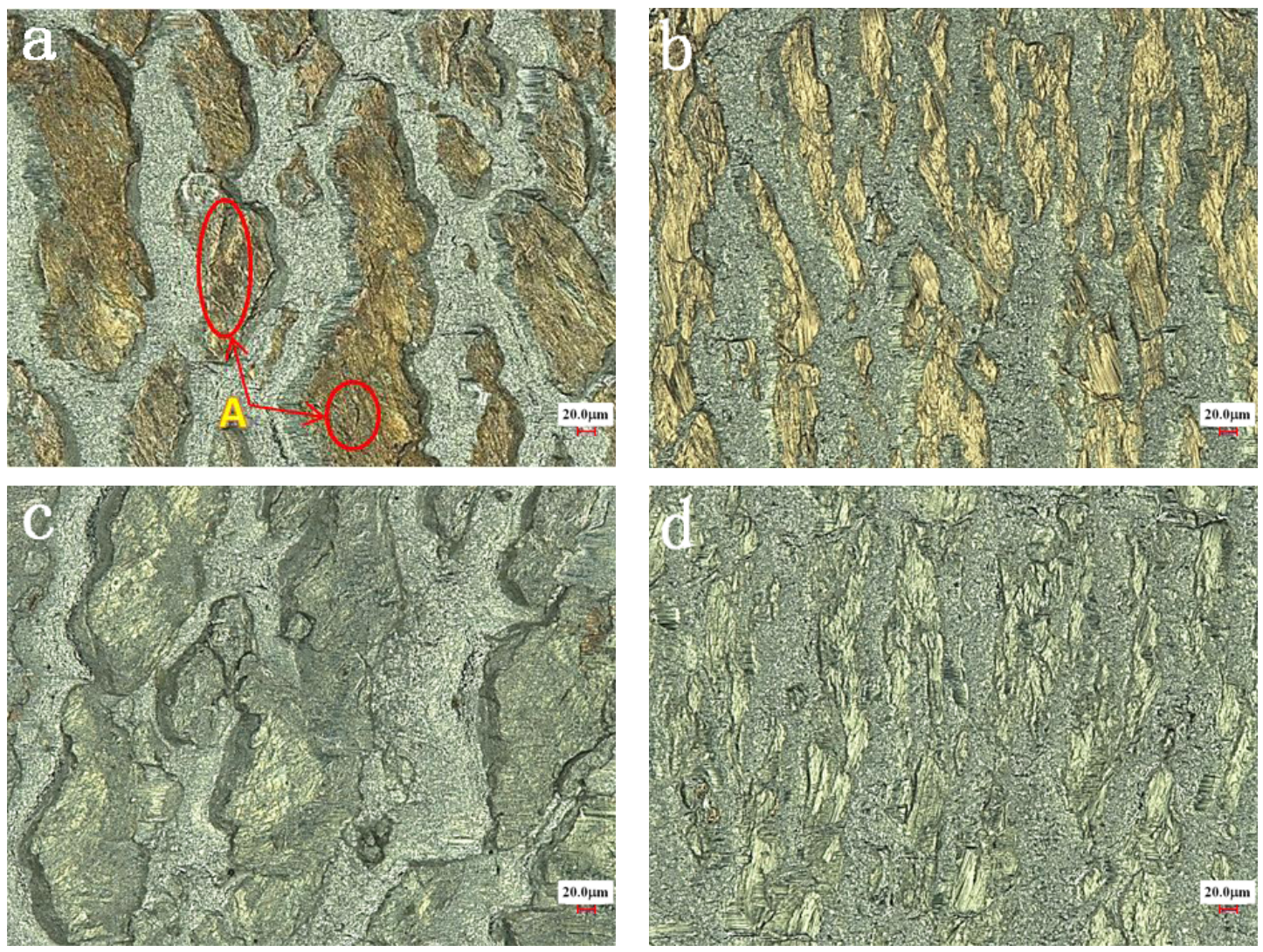

Figure 5. Optical microscopy using a super depth of field 3D microscope system showing the combined interface morphology: (a) unpulsed copper side; (b) pulse copper side; (c) unpulsed aluminum side; (d) pulse aluminum side.

Figure $6 \mathrm{a}, \mathrm{c}$ shows the element distribution and proportion of the copper-side shear interface of the $\mathrm{Cu} / \mathrm{Al}$ laminated composite without pulse current-assisted rolling. Figure $6 \mathrm{~b}, \mathrm{~d}$ shows the element distribution and proportion of the copper-side shear interface of the $\mathrm{Cu} / \mathrm{Al}$ laminated composite by pulse current-assisted rolling. In Figure $6 a$, it can be clearly seen that there were a large number of copper regions $\mathrm{M}$ without aluminum embedding on the copper-side shear interface of the $\mathrm{Cu} / \mathrm{Al}$ laminated composite without pulse current-assisted rolling. From the area A in Figure 5a, it can be seen that a relatively slender crack appears in the area M. It shows that these small cracks were not firmly embedded in the aluminum metal during the rolling process. As shown in the area $\mathrm{N}$ of Figure $6 \mathrm{~b}$, a large amount of fine aluminum was embedded in the copper thin plate besides the thick reticulated ridges on the copper side shear interface of the $\mathrm{Cu} / \mathrm{Al}$ laminated composite after pulse current-assisted rolling. The appearance of the larger copper area $\mathrm{M}$ was reduced. It is due to the increase in the number of large cracks and the appearance of more small cracks under the pulsed current-assisted rolling. At the same time, the plasticity of aluminum was improved. This resulted in an increase in 
the amount of aluminum metal that was firmly embedded in the copper sheet. This is due to the joule heat generated by the pulse current, which causes an instantaneous rise in the temperature of the $\mathrm{Cu} / \mathrm{Al}$ laminated composite. In pulsed current-assisted rolling, a large number of electrons with a certain drift velocity collide with the atoms when the current passes through the $\mathrm{Cu} / \mathrm{Al}$ laminated composite. Joule heat energy will be generated in a moment under the impact of electron flow collision. The heating rate of metal can reach $10^{6}{ }^{\circ} \mathrm{C} / \mathrm{S}^{-1}$ order of magnitude. Such high-speed heating can be regarded as a short-time insulation heating process. The average temperature rise of joule heat caused by electron movement can be expressed as Equation (1) [22].

$$
\Delta T=\left(c \rho S^{2}\right)^{-1} \int_{0}^{\infty} \gamma I^{2} d t(1)
$$

where $S$ : cross-sectional area of the sample; $I$ : peak pulse current; $t$ : corresponding pulse time; $c, \rho$ and $\gamma$ : specific heat, the density and the electrical resistivity of the material, respectively. The $\mathrm{Cu} / \mathrm{Al}$ laminated composite produced a transient temperature rise when subjected to the pulse current. The shear stress of the metal was reduced and the slip system increased due to the increase in temperature. At the same time, the kinetic energy of atoms increased and the bonding force between atoms was weakened due to the increase in temperature. Therefore, the plasticity of aluminum was improved by the new slip system participating in the slip. Under the effect of rolling force, aluminum was more likely to be squeezed into the cracks on the copper surface. The aluminum and copper in the crack were more closely combined. The solid embedding of aluminum in this small crack plays a reinforcing role in the combination of $\mathrm{Cu} / \mathrm{Al}$ laminated composite.

Figure 7a shows the SEM image of the shearing interface of the $\mathrm{Cu} / \mathrm{Al}$ laminated composite on the copper side without pulse current-assisted rolling. Figure 7c shows the proportion of elements at point $\mathrm{P}$ in Figure 7a. Figure $7 \mathrm{~b}$ shows the SEM image of the shearing interface of the $\mathrm{Cu} / \mathrm{Al}$ laminated composite on the copper side by pulse current-assisted rolling. Figure $7 \mathrm{~d}$ shows the proportion of elements at point $Q$ in Figure 7b. It can be seen from Figure 7a that the copper area of the shear surface was relatively smoothed without the application of pulse current to assist rolling. Figure $7 \mathrm{~b}$ there were obvious folds in the copper area of the shear interface during the application of pulse current-assisted rolling. The $\mathrm{Cu} / \mathrm{Al}$ laminated composite produced an instantaneous temperature rise in the applied pulsed current-assisted rolling. The folds on the copper surface increased significantly when the $\mathrm{Cu} / \mathrm{Al}$ laminated composite were heated. Due to the better plasticity of aluminum, the surface structure was deformed when contacting hard copper. From a microscopic point of view, the corrugated concave area of the copper area (as shown in Figure $7 \mathrm{~b}$ ) was properly filled with aluminum under the effect of rolling force, and the location of the corrugated protrusion of the copper area was wrapped by aluminum. The aluminum was filled in a complementary manner according to the shape of the folds on the surface of the copper. In this process of complementation, interfacial interlock occurs between the aluminum metal filled into the copper fold and the raised copper. Therefore, there was redundant friction between the folds on the copper surface and the aluminum. This structural form increases the frictional driving force and enhances the shear strength of the laminated composite. At the same time, the lateral wall of the fold was exposed to the surface, so that the contact area increased at the bonding interface. The wall of the corrugated side is composed of fresh metal atoms that are exposed and unsaturated in the metal bond, and achieve good interfacial bonding with aluminum atoms. As shown in Figure 7b, the point $Q$ was a small convex point with high aluminum content on the surface of copper. It showed that the folds enhanced the bonding strength of $\mathrm{Cu} / \mathrm{Al}$ laminated composite to a certain extent. 


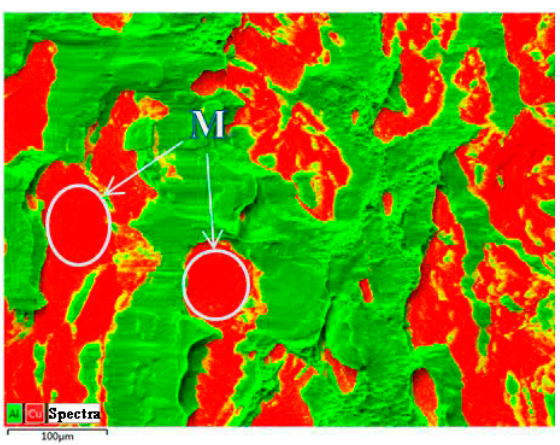

(a)

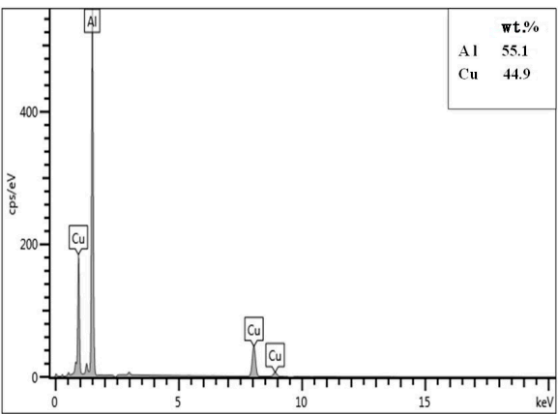

(c)

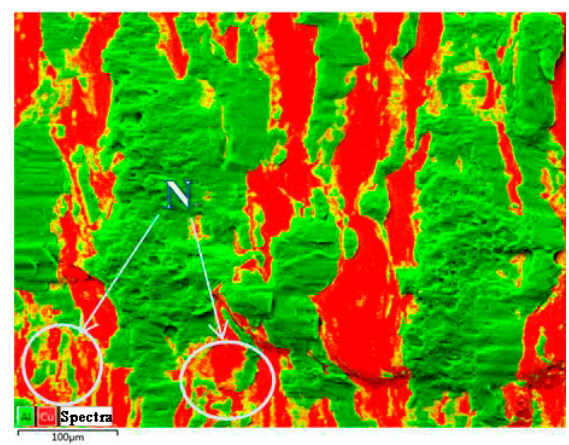

(b)

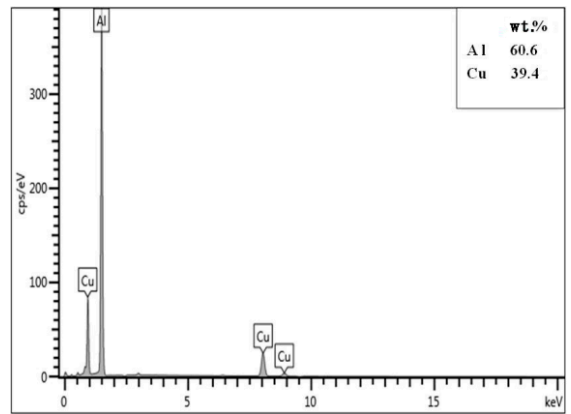

(d)

Figure 6. EDS spectra of the shear interface on the copper side: (a) unpulsed copper side element surface distribution; (b) pulse copper side element surface distribution; (c) proportion of the element surface distribution of unpulsed copper side; (d) proportion of the element surface distribution of pulse copper side.

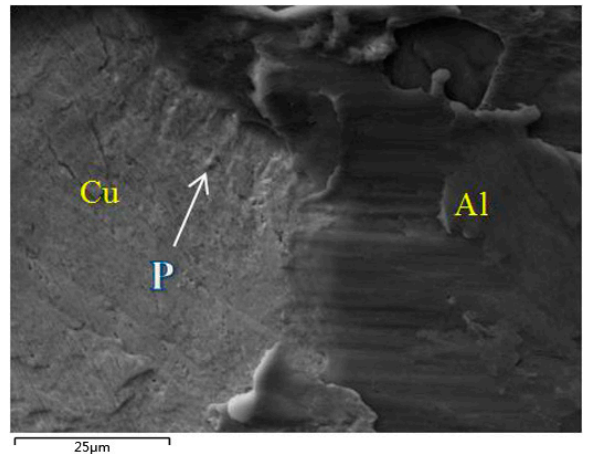

(a)

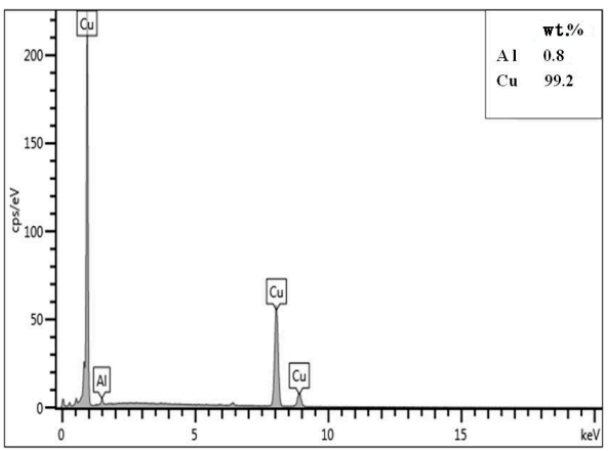

(c)

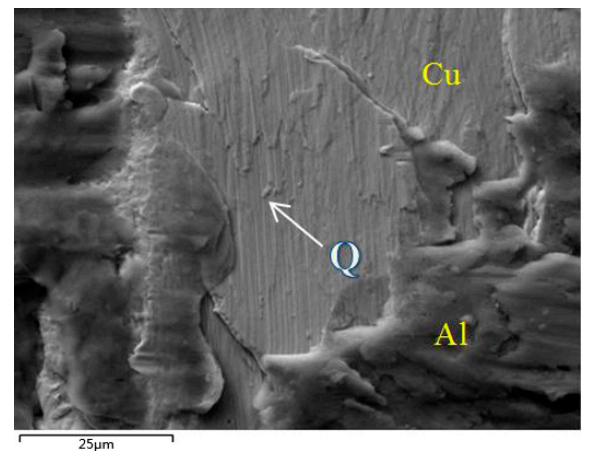

(b)

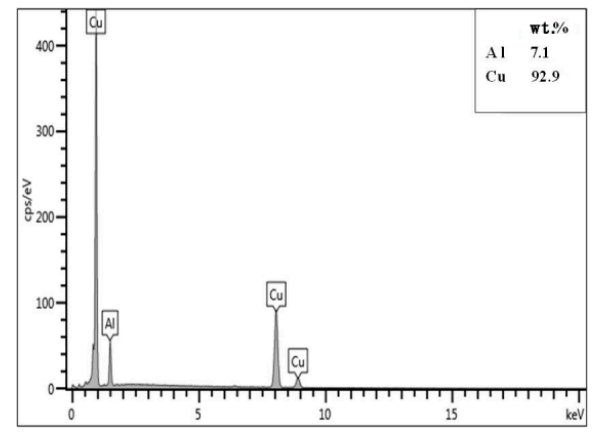

(d)

Figure 7. Image of the shear interface on the copper side. (a) Unpulsed copper side; (b) pulse copper side; (c) proportion of elements at point $\mathrm{P}$; (d) proportion of elements at point $\mathrm{Q}$. 


\subsection{The Effect of Different Rolling Processes on the Bonding Interface}

Figure 8 a,c show the SEM images of $500 \times$ and $3000 \times$ at the bonding interface without pulse current-assisted rolling. Figure 8e shows the distribution diagram of element diffusion at the bonding interface without pulse current-assisted rolling. In Figure 8a, it can be seen that the combined interface was corrugated and relatively smooth. The average distance between the interface crest and trough was $72 \pm 5 \mu \mathrm{m}$. Figure $8 \mathrm{~b}$,d show the SEM images of $500 \times$ and $3000 \times$ at the bonding interface under pulse current-assisted rolling. Figure $8 \mathrm{f}$ shows the distribution diagram of element diffusion at the bonding interface under pulse current-assisted rolling. In Figure $8 b$, it can be seen that the combined interface was corrugated and relatively roughed. The average distance between the interface crest and trough was $38 \pm 5 \mu \mathrm{m}$. It can be seen from Figure $8 \mathrm{~d}$ that the $\mathrm{Cu} / \mathrm{Al}$ laminated composite had obvious serrated protrusions on the crest and trough of the bonding interface. This corrugated interface with serrated protrusions proves that the plasticity of the $\mathrm{Cu} / \mathrm{Al}$ laminated composite has been enhanced to a certain extent. At the same time, the morphology of the bonding interface is a key factor affecting the bonding strength of the $\mathrm{Cu} / \mathrm{Al}$ laminated composite. The difference in the bonding interface results in a significantly different bonding effect. For shear strength, the Combined Area Ratio (CAR) is an important indicator. The mathematical expression of CAR is shown in Equation (2).

$$
\mathrm{CAR}=C / R
$$

where $C$ : cross-sectional area of a metal embedded in another metal; $R$ : cross-sectional area of another metal. The size of the CAR was influenced by the configuration of the bonding interface. The shear strength of the laminated composite has a positive correlation with the CAR value. The difference in the spacing between the crests and troughs can significantly affect the shear strength of the laminated composite. The average distance between the crests and troughs was reduced at the $\mathrm{Cu} / \mathrm{Al}$ laminated composite bonding interface by applying pulsed current to assist rolling. There were obvious serrated protrusions on the crests and troughs. This bonding interface morphology increases the Combined Area Ratio. The shear strength of the bonding interface of $\mathrm{Cu} / \mathrm{Al}$ laminated composite was improved. The shear force was composed of friction and intermolecular force between the copper sheet and the aluminum sheet. In addition to the friction generated by the above structure, the bond formed by the interdiffusion of atoms between the composite interfaces plays a role to improving the shear strength. The copper sheet and aluminum sheet were rolled on top of each other to form a diffusion couple. It can be seen from Figure $8 \mathrm{f}$ that the thickness of the interface diffusion layer of $\mathrm{Cu} / \mathrm{Al}$ laminated composite increased to a certain extent when pulse current was applied. In the pulsed current-assisted rolling process, the temperature of the composite interface rises instantaneously due to the pulsed current passing through the metal interior. The higher reaction temperature promotes the increase of the interfacial diffusion coefficient. It was easier for interdiffusion to occur at the composite interface of $\mathrm{Cu} / \mathrm{Al}$ laminated composite. Therefore, the thickness of the interfacial diffusion layer was thicker than that of $\mathrm{Cu} / \mathrm{Al}$ laminated composite without pulse current-assisted rolling. The increase of the thickness of the interface layer had a certain effect on the improvement of the bonding strength of the $\mathrm{Cu} / \mathrm{Al}$ laminated composite. 

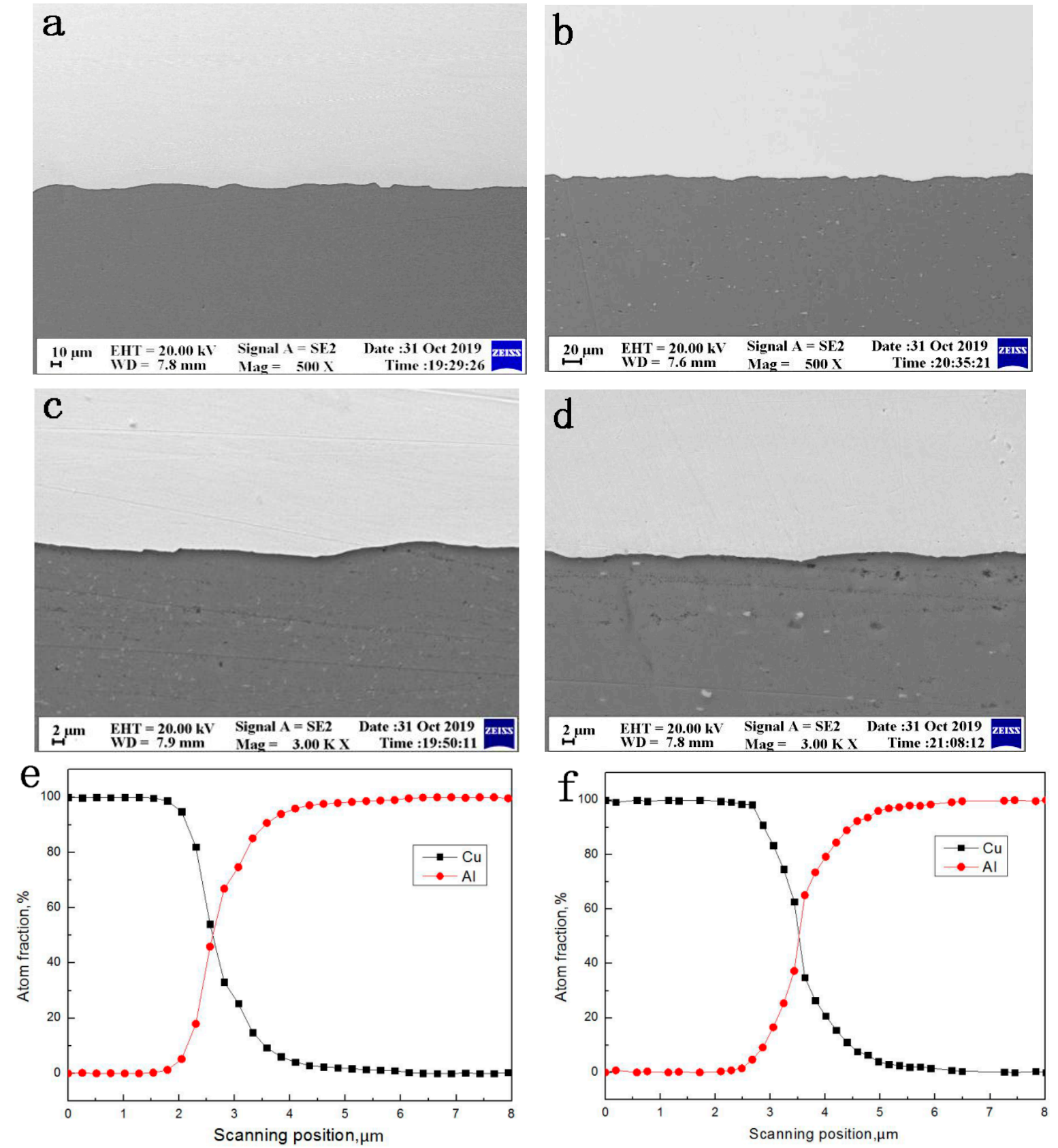

Figure 8. SEM image and diffusion image of the element at the bonding interface: (a) $500 \times$ unpulsed; (b) $500 \times$ pulse; (c) $3000 \times$ unpulsed; (d) $3000 \times$ pulse; (e) unpulsed interface element diffusion; (f) pulse interface element diffusion.

\section{Conclusions}

With the application of pulse current-assisted rolling $\mathrm{Cu} / \mathrm{Al}$ laminated composite, the density of the reticulated ridge was significantly increased on the copper-side interface of the shear specimen. The increase in reticulated ridges indicates that more aluminum was anchored to the copper sheet. This anchoring effect effectively hinders the deep sliding of the copper sheet, thereby achieving the purpose of enhancing the bonding strength.

The plastic deformation ability of the aluminum sheet was improved by applying pulse current to assist the rolling. The small cracks on the copper surface were firmly embedded in the aluminum metal. This solid embedding plays a reinforcing role in the combination of $\mathrm{Cu} / \mathrm{Al}$ laminated composite. 
There were obvious folds on the surface of the copper through the application of pulse current-assisted rolling, which increases the surface roughness of the copper. The complementary filling was carried out between the copper surface and the aluminum surface. In this complementary process, the interlocking phenomenon occurs between the aluminum metal filled in the copper folds and the raised copper folds. This interface structure plays a certain role in enhancing the bonding strength of $\mathrm{Cu} / \mathrm{Al}$ laminated composite.

Author Contributions: Conceptualization, H.S., W.H. and X.M.; formal analysis, H.S., funding acquisition, T.H. and C.C.; investigation, H.S., W.H. and X.M.; methodology, H.S., W.H., X.M. and G.G.; project administration, T.H., C.C. and G.G.; software, X.M. and T.H.; supervision, W.H. and C.C.; validation, W.H.; visualization, X.M.; writing—original draft, H.S., W.H., X.M., T.H., C.C. and G.G.; writing-review and editing, H.S., W.H., X.M., T.H., C.C. and G.G.; All authors have read and agreed to the published version of the manuscript.

Funding: This work was supported by National Natural Science Foundation of China (grant numbers 51905366); Scientific and Technological Innovation Programs of Higher Education Institutions in Shanxi (grant numbers 2019L0632); Taiyuan University of Science and Technology Scientific Research Initial Funding (grant numbers 20182030 and 20192008); National Natural Science Foundation of China (grant numbers 51901149); Tai Yuan University Of Science And Technology Scientific Research Initial Funding (grant numbers 20192003); Youth Science and Technology Research Fund in Shanxi (grant numbers 201901D211307); Scientific and Technological Innovation Programs of Higher Education Institutions in Shanxi (STIP) (grant numbers 2019L0625).

Conflicts of Interest: The authors declare that there are no conflicts of interest regarding the publication of this paper.

\section{References}

1. Tseng, H.-C.; Hung, C.; Huang, C.-C. An analysis of the formability of aluminum/copper clad metals with different thicknesses by the finite element method and experiment. Int. J. Adv. Manuf. Technol. 2010, 49, 1029-1036. [CrossRef]

2. Shabani, A.; Toroghinejad, M.R.; Shafyei, A. Effect of post-rolling annealing treatment and thickness of nickel coating on the bond strength of Al-Cu strips in cold roll bonding process. Mater. Des. 2012, 40, 212-220. [CrossRef]

3. Guo, Y.J.; Liu, G.W.; Jin, H.Y.; Shi, Z.Q.; Qiao, G.J. Intermetallic phase formation in diffusion-bonded Cu/Al laminates. J. Mater. Sci. 2011, 46, 2467-2473.

4. Lee, J.H.; Bae, D.H.; Chung, W.S.; Kim, K.H.; Cho, Y.R. Effects of annealing on the mechanical and interface properties of stainless steel/aluminum/copper clad-metal sheets. J. Mater. Process. Technol. 2007, 187-188, 546-549.

5. Chen, C.-Y.; Hwang, W.-S. Effect of Annealing on the Interfacial Structure of Aluminum-Copper Joints. Mater. Trans. 2007, 48, 1938-1947. [CrossRef]

6. Gulenc, B. Investigation of interface properties and weldability of aluminum and copper plates by explosive welding method. Mater. Des. 2008, 29, 275-278. [CrossRef]

7. Jeong, E.-W.; Hui, K.; Bae, D.-H.; Cho, Y.R.; Bae, D.-S. Identification of the intermetallic compound layer formed at the interface of roll-bonded aluminum-clad steel by thermal annealing. Met. Mater. Int. 2014, 20, 499-502. [CrossRef]

8. Sun, X.-J.; Tao, J.; Guo, X.-Z. Bonding properties of interface in Fe/Al clad tube prepared by explosive welding. Trans. Nonferrous Met. Soc. China 2011, 21, 2175-2180. [CrossRef]

9. Guo, Y.; Qiao, G.; Jian, W.; Zhi, X. Microstructure and tensile behavior of $\mathrm{Cu}-\mathrm{Al}$ multi-layered composites prepared by plasma activated sintering. Mater. Sci. Eng. A 2010, 527, 5234-5240. [CrossRef]

10. Li, B.; Chen, Z.; He, W.; Wang, P.; Lin, J.; Wang, Y.; Peng, L.; Li, J.; Liu, Q. Effect of interlayer material and rolling temperature on microstructures and mechanical properties of titanium/steel clad plates. Mater. Sci. Eng. A 2019, 749, 241.

11. Venkatesh, R.; Srinivas, S.; Ramamurthy, V. Effect of heat treatment on hardness, tensile strength and microstructure of hot and cold forged Al6061 metal matrix composites reinforced with silicon carbide particles. Mater. Res. Express 2019, 6, 10. [CrossRef]

12. Rastegari, H.; Asgari, S.; Abbasi, S. Producing Ti-6Al-4V/TiC composite with good ductility by vacuum induction melting furnace and hot rolling process. Mater. Des. 2011, 32, 5010-5014. [CrossRef]

13. Naseri, M.; Reihanian, M.; Borhani, E. Bonding behavior during cold roll-cladding of tri-layered Al/brass/Al composite. J. Manuf. Process. 2016, 24, 125-137. [CrossRef] 
14. Huang, H.J.; Li, X.Q.; Zuo, X.J. Effect of technological parameters on interface bonding of copper-aluminum-copper composite plate. J. Shenyang Univ.Techno. 2020, 42, 47-51.

15. Chen, C.-Y.; Chen, H.-L.; Hwang, W.-S. Influence of Interfacial Structure Development on the Fracture Mechanism and Bond Strength of Aluminum/Copper Bimetal Plate. Mater. Trans. 2006, 47, 1232-1239. [CrossRef]

16. Aizawa, T. Magnetic Pulse Welding of Al/Cu Sheets Using 8-Turn Flat Coil. Light Met. Weld. 2020, 52, 97-101.

17. Sarvari, M.; Abdollah-Zadeh, A.; Naffakh-Moosavy, H.; Rahimi, A.; Parsaeyan, H. Investigation of Collision Surfaces and Weld Interface in Magnetic Pulse Welding of Dissimilar Al/Cu Sheets. J. Manuf. Process. 2019, 45, 356-367. [CrossRef]

18. Chung, D.K.; Shin, H.S.; Park, M.S.; Chu, C.N. Machining characteristics of micro EDM in water using high frequency bipolar pulse. Int. J. Precis. Eng. Manuf. 2011, 12, 195-201. [CrossRef]

19. Wu, G.; Zhang, Z.; Zhang, W.; Tang, X. High frequency group pulse electrochemical machining. Front. Mech. Eng. China 2007, 2, 293-296. [CrossRef]

20. Xu, R.D.; Zhai, D.C.; Hu, S.L. Influences of Pulse Current Density on the Characteristics of Ni-W-P-CeO2-SiO2 Composite Coatings. Adv. Mater. Res. 2011, 418-420, 856-860.

21. Jia, W.T.; Ma, L.F.; Jiao, M.Y.; Le, Q.C.; Han, T.Z.; Che, C.J. Fracture criterion for predicting edge-cracking in Hot rolling of twin-roll casted AZ31 Mg alloy. J. Mater. Res. Technol. 2020, 9, 4773-4787. [CrossRef]

22. Song, H.; Wang, Z.-J. Improvement of mechanical properties of cold-rolled commercially pure Ti sheet by high density electropulsing. Trans. Nonferrous Met. Soc. China 2012, 22, 1350-1355. [CrossRef]

Publisher's Note: MDPI stays neutral with regard to jurisdictional claims in published maps and institutional affiliations.

(C) 2020 by the authors. Licensee MDPI, Basel, Switzerland. This article is an open access article distributed under the terms and conditions of the Creative Commons Attribution (CC BY) license (http://creativecommons.org/licenses/by/4.0/). 